\title{
The Effect of Personal Values on Employee's Innovative Behavior in Vietnamese Enterprises
}

\author{
Thi Thu Phuong Le, Thi Ha Phuong Phan, Thi Ngoc Quynh Hoang, and Thi Phuong Linh Nguyen
}

\section{ABSTRACT}

\begin{abstract}
Innovative behavior is becoming increasingly important, especially when the world has witnessed the rapid growth of start-up companies. The purpose of this research is to measure the impact of 10 kinds of personal values on innovative behavior of employees, based on Schwart's theory of basic values to build the research framework. A total of 455 Vietnamese respondents from different companies participated in this study. The type of this research is a quantitative research and we used SPSS 22.0 to analyze the data used in this study. The result showed that universalism and benevolence positively affected employee's innovative behavior. Whereas the other values were found to have no significance of innovative behavior in our research.
\end{abstract}

Keywords: innovative behavior, personal values, theory of basic values, Vietnam.

\author{
Submitted : March 07, 2021 \\ Published : May 21, 2021 \\ ISSN: 2507-1076 \\ DOI: $10.24018 /$ ejbmr.2021.6.3.804 \\ Thi Thu Phuong Le \\ National Economics University, Vietnam. \\ (e-mail: 11184003@st.neu.edu.vn) \\ Thi Ha Phuong Phan \\ National Economics University, Vietnam. \\ (e-mail: 11184093@ st.neu.edu.vn) \\ Thi Ngoc Quynh Hoang \\ National Economics University, Vietnam. \\ (e-mail: 11184230@ st.neu.edu.vn) \\ Thi Phuong Linh Nguyen* \\ National Economics University, Vietnam. \\ (e-mail: linhnp@neu.edu.vn) \\ *Corresponding Author
}

\section{INTRODUCTION}

In recent years, Vietnam has been one of the countries which have strongly considered start-up businesses. With the Start-up Support Scheme in the period 2019-2025, Vietnam's government enacted policies that support and motivate entrepreneurship by Vietnamese residents, especially the young generation. In this case, innovation has played an essential role in developing business, adapting to the international market, and being competitive with competitors. Besides, the economy of Vietnam has suffered slightly from the effects of Covid-19 pandemic. Many companies have dissolved because of being unable to achieve sustainable growth. In addition, enterprises must have more and more innovative initiatives to adapt to the business environment in the digital transformation era.

Regarding the context of Vietnam, there are a few researches that study the innovative behavior of employees. Those researches are still limited in sample size, and most of them are conducted in a few enterprises, so they have not covered the factors that influence employees' innovative behavior. Our research aims to help the enterprises understand innovative behavior and the effect of personal values on it; thus, they may have effective solutions to develop their employees. Moreover, this study will raise people's awareness of the importance of innovative behavior in organizations and how they can be more innovative in their work. Our research is based on Schwart's theory of basic human values [1] and extends to the role of personal values on innovative behavior of employees.

\section{LITERATURE REVIEW AND HYPOTHESIS DEVELOPMENT}

\section{A. Innovative Behavior}

In [2], innovative behavior is defined as an employee's intentional introduction or application of new ideas, products, processes, and procedures to their work role, work unit, or organization.

The authors [2] conceptualize innovative behavior as complex behavior consisting of activities about both the generation/introduction of new ideas (either by oneself or adopted from others) and the realization or implementation of new ideas.

\section{B. Personal Values}

Values may determine one's attitudes toward specific objects or situations, subsequently guiding the individuals' behavior and motivating their actions and attitudes [3].

\section{1) Self-Direction}

This value type is defined with the goal of independence in deciding action and thought, exploration, and creation. The requirements of independence and autonomy about interaction and controlling resulted in self-direction [1]. Selfdirection stems from the need for independence, autonomy, and control [4] To creativity, self-direction is assumed to be the most relevant value [5]. The reason is that creativity is a part of self-direction, its motivational goals would seem to be 
primary values for the ones with creativity as independent action and thought, freedom in pursuing the interests and exploring [5].

\section{2) Stimulation}

The values relating to stimulation are supposed to stem from the organismic needs for stimulation and diversity to keep the activation at the highest level [1]. According to [6], it seems that innovative behavior is promoted by the stimulation values as an approach to gaining goals.

\section{3) Achievement}

Achievement motivation is the need for excellence and significant accomplishment, despite what rewards may be offered after the achievement has been met [7]. This value type's defining goal is personal success by demonstrating competence according to social standards [1]. Achievement values emphasize demonstrating competence in prevailing cultural standards, thereby obtaining social approval [1]. On the other hand, this valued goal can be boosted by innovative activities. The reason is that the employees with innovative behavior may differentiate themselves from other co-workers by their notable position, which is recognized as their success [6].

\section{4) Power}

Power values may also transform the individual needs for dominance and control identified by analysts of social motives [1]. Power reflects the goals of prestige, social status attainment, and control or dominance over people and resources [6]. Employees can also be aware of innovative behaviour to pertain high social status and reach the important position of leader in comparison with others [6].

\section{5) Security}

The motivational goal of security values includes harmony, safety, and stability of relationships, of self, and of society. Individual and group requirements are presumed to be its foundation [1]. The priority of employees with the high level of security values is structure and certainty. Besides, they are very likely to clarify uncertainty as threatening [8]. On the contrary, employees with the low level of security values are more prone to hold the change [8]. This value type seems to decrease innovative behavior due to that they concentrate on harmony, safety, and stability, which prevent them from innovation implementation. Particularly, executing innovations in firms often demands disrupting formed standards, process, conventions [6].

\section{6) Conformity}

Restraint of actions, inclinations, and impulses likely to bother or harm others and violate social expectations or norms is the defining goal of this value type [1]. As being given define, conformity values stress self-restraint in everyday interaction, usually with close ones (obedient, honoring parents and elders, politeness, self-discipline) [1]. According to [6], employees have the intention to avoid performing innovative initiatives when they attach high significance to this value because it may result in changes that others do not easily accept or welcome in their organizations.

\section{7) Tradition}

This value refers to honoring and preserving cultural traditions and customs [9]. This domain may also be grounded in the universal survival needs of groups [9]. The motivational goal of tradition values is showing commitment, acceptance and respect to the customs as well as ideas of other culture or religion that impose on the individual [1]. Innovative behaviors are not fit in that approach and are not supposed to be motivated in such an environment. Employees who want to perform their innovative ideas in organizations should take the initiative and attempt to realize ideas, which sometimes requires substantial efforts [6]

\section{8) Hedonism}

Hedonism shares elements of both self-enhancement and openness to change [9]. Scholars from many disciplines referred to this value type which descends from organismic needs and the pleasure related to satisfying them [1]. In order to justify including two values from the Rokeach list, happiness and cheerful, it used to be called enjoyment [1]. Hedonism is a human value which derived from the motivational goal of pleasure or sensuous gratification for oneself [10]. Hedonic values involved with the needs of seeking pleasure, which is even reflected in more intense shopping activities [10].

\section{9) Benevolence}

Benevolence values descend from the organismic need for affiliation and the essential requirement for smooth group functioning [9]. Benevolence involves concern that is shown in everyday interactions for relatively close people [6]. Benevolence values derived from the motivational goal of enhancement and preservation of the welfare of people with whom one is in frequent personal contact (helpful, loyal, forgiving, honest, responsible, true friendship, mature love) [1]. Behaviors such as helping others, donating money, voicing constructive suggestions, and volunteering, with demonstrating social sensitivity, awareness concerning moral, and showing readiness for social contact with outgroup members are related positively to Benevolence values [11].

\section{0) Universalism}

Universalism derived from the motivational goal of tolerance, appreciation, understanding, and protection for the welfare of all people and for nature [1]. The motivational goal of universalism values can be descended from those collective survival needs and individuals that become apparent when people interact with those outside the extended primary group and increase awareness of the scarcity of natural resources [1]. Universalism values show concern and tolerance for all others (e.g., social justice, equality, broad-mindedness) [12]. Together with benevolence, the values express the individuals' basic need to build social relations with other people and are consistently ranked as the most important values for most people across cultures [12].

\section{Previous Research}

Based on the previous research's result, hedonism, stimulation and self-direction were found to have a positive effect on individual innovative behaviors [6], [13]. Another found that both power and achievement values are positively related to innovation in organizations among employees in managerial positions [3]. 
However, some studies found that security, conformity, tradition and universalism, benevolence negatively related to innovative behavior [5], [6].

\section{Conceptual Framework}

From previous researches stated above, the authors propose the theoretical framework below:

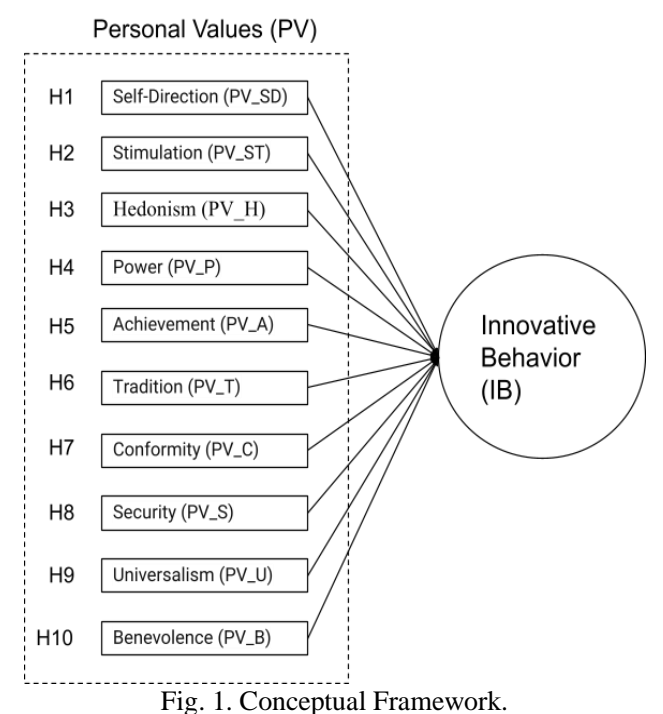

The hypotheses in this study can be described as below based on the shown conceptual framework:

Hypothesis 1 (H1): Self-Direction has a positive effect on innovative behavior.

Hypothesis 2 (H2): Stimulation has a positive effect on innovative behavior.

Hypothesis 3 (H3): Hedonism has a positive effect on innovative behavior.

Hypothesis 4 (H4): Power has a positive effect on innovative behavior.

Hypothesis 5 (H5): Achievement has a positive effect on innovative behavior.

Hypothesis 6 (H6): Tradition has a negative effect on innovative behavior.

Hypothesis 7 (H7): Conformity has a negative effect on innovative behavior.

Hypothesis 8 (H8): Security has a negative effect on innovative behavior.

Hypothesis 9 (H9): Universalism has a negative effect on innovative behavior.

Hypothesis 10 (H10): Benevolence has a negative effect on innovative behavior.

\section{RESEARCH METHODOLOGY}

\section{A. Source of Data}

Primary and secondary methods are used for collecting data. The authors used an online survey for collecting primary data by a structured questionnaire. Tools such as Google Scholar, ScienceDirect, Emerald Insight, and Proquest were used for collecting secondary data.

\section{B. Questionnaire}

In this study, the authors referenced Portrait Values Questionnaire with 21 items (PVQ-21) to calculate employees' personal values. According to [15], [16], the measure is uncomplicated and even applicable to the employees who do not go to school or have little academic knowledge. The statements in this measure help to describe various people's verbal portrait to show the influence of each type of value [14]. Variables were measured on a Likert scale from 1 (strongly disagree) to 5 (strongly agree).

\section{Methods of Data Analysis}

From the valid questionnaires collected, the authors turned to Excel and coded each part of the survey questionnaire. Next, all data were processed through the SPSS 22.0 software. The authors conducted three steps of analyses and testing: firstly, Cronbach's alpha analysis and explorative factor analysis (EFA) are implemented to assess variables' reliability. Secondly, the authors use linear regression analysis for estimating the relationship among variables.

\section{IV.RESULTS}

\section{A. Respondent Characteristics}

As the data of 455 respondents that the authors collected, it shows that most employees are women (55.6\%), age $20-30$ years $(74.9 \%)$, 6-10 years of working experience $(42.6 \%)$, below 5 million VND of income $(27.7 \%)$ and with firm size of $50-100$ people $(32.1 \%)$. The fields of respondents are mainly relating to finance $(18.7 \%)$, education $(15.6 \%)$, and real estate $(10.1 \%)$.

\section{B. Reliability Analysis}

In this study, we conducted to verify Cronbach's Alpha reliability with each value to evaluate the scale's internal consistency and delete the low-reliability items. For exploratory studies, values between 0.60 and 0.70 are considered acceptable [17], [18]. In Table I, we present the results of the reliability analysis of the indicators:

\begin{tabular}{|c|c|c|c|c|}
\hline $\begin{array}{c}\text { Cronbach's } \\
\text { Alpha }\end{array}$ & Items & $\begin{array}{c}\text { Scale } \\
\text { Variance } \\
\text { if Item } \\
\text { Deleted }\end{array}$ & $\begin{array}{c}\text { Corrected } \\
\text { Item-Total } \\
\text { Correlation }\end{array}$ & $\begin{array}{c}\text { Cronbach's } \\
\text { Alpha if Item } \\
\text { Deleted }\end{array}$ \\
\hline \multirow{2}{*}{0.921} & PV_SD1 & 0.729 & 0.854 & \\
\hline & PV_SD2 & 0.746 & 0.854 & \\
\hline \multirow[t]{2}{*}{0.716} & PV_ST1 & 0.587 & 0.558 & \\
\hline & PV_ST2 & 0.591 & 0.558 & \\
\hline \multirow{2}{*}{0.803} & PV_H1 & 0.719 & 0.679 & \\
\hline & PV_H2 & 0.528 & 0.679 & \\
\hline \multirow[t]{2}{*}{0.816} & PV_A1 & 0.557 & 0.691 & \\
\hline & PV_A2 & 0.495 & 0.691 & \\
\hline \multirow[t]{2}{*}{0.765} & PV_P1 & 1.009 & 0.626 & \\
\hline & PV_P2 & 0.747 & 0.626 & \\
\hline \multirow[t]{2}{*}{0.916} & PV_S1 & 0.588 & 0.845 & \\
\hline & PV_S2 & 0.556 & 0.845 & \\
\hline \multirow[t]{2}{*}{0.787} & PV_C1 & 0.578 & 0.649 & \\
\hline & PV_C2 & 0.612 & 0.649 & \\
\hline \multirow[t]{2}{*}{0.887} & PV_T1 & 0.943 & 0.796 & \\
\hline & PV_T2 & 0.942 & 0.796 & \\
\hline \multirow[t]{2}{*}{0.845} & PV_B1 & 0.763 & 0.732 & \\
\hline & PV_B2 & 0.814 & 0.732 & \\
\hline \multirow[t]{3}{*}{0.768} & PV_U1 & 1.693 & 0.572 & 0.720 \\
\hline & PV_U2 & 1.640 & 0.628 & 0.658 \\
\hline & PV_U3 & 1.651 & 0.603 & 0.685 \\
\hline
\end{tabular}

Cronbach's Alpha coefficients of personal value factors were all greater than 0.70 , showing a reasonable scale. Based 
on Table I, in addition to the factors of personal value of universalism PV_U), conformity (PV_C), power (PV_P) and stimulation (PV_ST), the rest of the ten values had Cronbach's Alpha coefficient greater than 0.80 , which led to an excellent scale. Therefore, the authors concluded that the scale of personal values had good reliability.

\section{Exploratory Factor Analysis}

The authors consider 25 items to calculate innovative behavior and 10 aspects of personal values: self-direction and stimulation, hedonism, power, achievement, tradition, conformity, security, universalism, benevolence. Each aspect was estimated by two items, except for universalism and innovative behavior, with three and four items, respectively. In this study, the statistical criteria were satisfied.

Bartlett's Test of Sphericity value $[\chi 2=4611,839 ; \mathrm{p}<$ $0.001]$ was significant, rejecting the null hypothesis that the correlation matrix was an identity matrix. Besides, the KMO value was $0.612>0.50$, which illustrated the availability of a proper number of items for each factor.

The next step was to identify eigenvalues, percentage of variances and factor loading. In the current study, 11 factors with eigenvalues over 1 emerged from the EFA, explaining $80,854 \%$ of the total variance.

The authors deployed the component matrix after varimax rotation to determine the items relating to each factor. On the other hand, all chosen 25 items with high loading factors ranging from 0.776 to $0.955(>0.50)$ were entered in list. From EFA, the authors extracted 11 factors to continue the step of linear regression analysis.

\section{Linear Regression Analysis}

This section of the study presents the results and discussions of the regression output. To examine the impact of the relationship between personal values and employee's innovative behavior, regression model was estimated. The regression analysis enables the researcher to empirically test the proposed hypothesis and to achieve the research objective.

From the findings, the adjusted $\mathrm{R}_{2}$ was used to establish the predictive power of the study model; however, it was found to be 0.075 , implying that changes in personal values explain $7.50 \%$ of the variations in employee's innovative behavior. The probability value of $0.000^{\mathrm{b}}$ indicates that the regression relationship was highly significant in predicting how personal values influenced innovative behavior.

\begin{tabular}{cccccc}
\multicolumn{5}{c}{ TABLE II: ANOVA } \\
\hline Model & $\begin{array}{c}\text { Sum of } \\
\text { Squares }\end{array}$ & df & $\begin{array}{c}\text { Mean } \\
\text { Square }\end{array}$ & F & Sig \\
\hline Regression & 12.738 & 10 & 1.274 & 4.690 & $0.000^{\mathrm{b}}$ \\
Residual & 120.592 & 444 & 0.272 & & \\
Total & 133.330 & 454 & & & \\
\hline
\end{tabular}

The analysis results also showed that eight out of ten values have no significance to employee's innovative behavior. They were stimulation, self-direction, hedonism, power, achievement, security, conformity, and tradition. Therefore, hypothesis $\mathrm{H} 1-\mathrm{H} 8$ were rejected or $\mathrm{H} 9$ and $\mathrm{H} 10$ were accepted.

Universalism $(B=0.104, p=0.024)$ and benevolence $(B=0.233, p<0.001)$ were the values positively relating to employees' innovative behavior. Besides, benevolence values impacted more than universalism values.

\begin{tabular}{cccc}
\multicolumn{4}{c}{ TABLE III: COEFFICIENTS OF LINEAR REGRESSION } \\
\hline Model & Beta & $\mathrm{t}$ & Sig. \\
\hline PV_SD & -0.006 & -0.128 & 0.898 \\
PV_ST & 0.039 & 0.827 & 0.409 \\
PV_H & -0.047 & -0.986 & 0.325 \\
PV_A & -0.019 & -0.406 & 0.685 \\
PV_P & 0.016 & 0.335 & 0.738 \\
PV_S & 0.069 & 1.341 & 0.181 \\
PV_C & 0.049 & 1.041 & 0.299 \\
PV_T & 0.037 & 0.788 & 0.431 \\
PV_B & 0.233 & 4.934 & 0.000 \\
PV_U & 0.104 & 2.270 & 0.024 \\
\hline
\end{tabular}

\section{CONCLUSION AND RECOMMENDATIONS}

From the results, the conclusion can be drawn based on proving the hypotheses that were built in this study. This research showed that personal values have a positive impact on employee innovative behavior. This study includes 10 factors that belong to personal values, but just universalism and benevolence are the aspects that exert a positive and significant impact on innovative behavior. Thus, employers could have possible solutions to improve current company status and build strategies to promote innovative employee initiatives by encouraging these values inside employees. Furthermore, the senior manager should reasonably assign tasks, especially teamwork which stimulates employee's benevolence. In this case, they will be willing to help their team to do tasks better and better. In addition, to promote innovative behavior, the employer should let the higherexperience employees support fresh ones. Moreover, the company might organize some volunteer activities and let their employees participate. Thus, the company not only improve their image but also show responsibilities to the social.

\section{REFERENCES}

[1] Schwartz, S., Basic human values: Theory, measurement, and applications. Revue Francaise de Sociologie, 2006. 47: p. 929968+977+981.

[2] Yuan, F. and R.W.J.A.o.m.j. Woodman, Innovative behavior in the workplace: The role of performance and image outcome expectations. 2010. 53(2): p. 323-342.

[3] Taştan, D.D.S. and S. Davoudi, The relationship between organisational climate and organisational innovativeness: testing the moderating effect of individual values of power and achievement International Journal of Business Innovation and Research, 2017. 12: p. 465.

[4] Sousa, C. and F. Coelho, From personal values to creativity: Evidence from frontline service employees. European Journal of Marketing, 2011. 45: p. 1029-1050.

[5] Dollinger, S.J., P.A. Burke, and N.W. Gump, Creativity and Values. Creativity Research Journal, 2007. 19(2-3): p. 91-103.

[6] Purc, E. and M. Laguna, Personal Values and Innovative Behavior of Employees. 2019. 10(865).

[7] Hsieh, P.-H., Achievement Motivation, in Encyclopedia of Child Behavior and Development, S. Goldstein and J.A. Naglieri, Editors. 2011, Springer US: Boston, MA. p. 20-21.

[8] Grant, A. and N. Rothbard, When in Doubt, Seize the Day? Security Values, Prosocial Values, and Pro activity Under Ambiguity. The Journal of applied psychology, 2013. 98.

[9] Schwartz, S., An Overview of the Schwartz Theory of Basic Values. Online Readings in Psychology and Culture, 2012. 2. 
European Journal of Business and Management Research www.ejbmr.org

[10] Hoffmann, S., et al., Under Which Conditions Are Consumers Ready to Boycott or Buycott? The Roles of Hedonism and Simplicity. Ecological Economics, 2018. 147: p. 167-178.

[11] Arieli, S., A. Grant, and L. Sagiv, Convincing Yourself to Care About Others: An Intervention for Enhancing Benevolence Values. Journal of personality, 2013. 82

[12] Arieli, S. and O. Tenne-Gazit, Values and Behavior in a Work Environment: Taking a Multi-level Perspective. 2017. p. 115-141.

[13] Kasof, J., et al., Values and Creativity. Creativity Research Journal, 2007. 19(2-3): p. 105-122.

[14] Schwartz, S., A proposal for measuring value orientations across nations. Questionnaire Package of ESS, 2003: p. 259-290.

[15] Cieciuch, J., Kształtowanie się systemu wartości od dzieciństwa do wczesnej dorostości. 2013: Wydawnictwo Liberi Libri.

[16] Roccas, S. and L. Sagiv, Values and behavior: Taking a cross cultural perspective. 2017: Springer.

[17] Hair, J., et al., A Primer on Partial Least Squares Structural Equation Modeling. 2014.

[18] Nunnally, J. and I. Bernstein, Psychometric Theory. 1994. 